\title{
One-Day Biopsy: An Experience Environment for Value Co-Creation in Health Services
}

\author{
Antonio Sergio da Silva ${ }^{1}$, Maria Aparecida Gouvêa ${ }^{2}$, \\ João Paulo Ferraz de Barros ${ }^{3}$, Fabrício Próspero Machado ${ }^{4}$, Silvio Fontana Velludo ${ }^{5}$, \\ Marcio Henrique de Alvarenga Nascimento ${ }^{6}$, Dailiane Luzia Margoto Nascimento ${ }^{7}$, \\ Anderson Luis de Alvarenga Nascimento ${ }^{8}$ \\ ${ }^{1,2}$ Universidade de São Paulo, São Paulo, Brazil \\ $1,3,4,5,6,7,8$ Instituto Prevent Senior, São Paulo, Brazil
}

\begin{abstract}
:
Background: Customers nowadays influence any business, anywhere all over the world, so that no company can operate completely autonomously. The interaction between the company and the customer experience forms the basis for the value co-creation.

Methods: This research proposes a descriptive framework for an experience environment of a co-creation network configuration in health services.

Results: This paper can be valuable as a means of pulling together what is known about co-creation frameworks, not simply assembling and describing past work but rather describing an applicable model in a breast cancer diagnosis center.

Conclusion: Clodomiro Amazonas Breast Cancer Diagnosis Center is a successful form of engagement platform where people congregate with the specific purpose and a structured process through which they will co-create, thereby playing a central role in the health service experience to qualify breast cancer care and address it in a timely manner.
\end{abstract}

Keywords: co-creation, healthcare, consumer behavior.

\section{INTRODUCTION}

Health services affect economies worldwide, and the people's quality of life (Berry \&Bendapudi, 2007). In recent years, research on the impact of services on people's well-being has been considered as a global priority. The future of research in services leans to topics of practical relevance (Ostrom et al., 2010). The quality of life depends both on the customer experience with the quality of services in social systems, as on the experience of employees with the quality of opportunities in their duties, in these same social systems (Spohrer et al., 2010).

Customers, under a traditional perspective, are seen as passive recipients of organizations (Payne, Storbacka \& Frow, 2008). However, from the phenomena of globalization and the spread of information through the Internet, customers assume, increasingly, an active and reflective role in contemporary society (Ueda et al., 2009). Equally, patients take, increasingly, a position of participation in decisions about their health, both active and reflective (McColl-Kennedy et al., 2013).

Creating unique experiences of value for customers seems to be the goal that drives the market in these first two decades of the twenty-first century. Despite the growing recognition of the importance of the subject, academic studies in this area are still limited and, in general, are directed to management actions and results, thus being few the studies about the background and the resulting customer experience (Verhoef et al., 2012).

Organizations should direct a look at the environment beyond its borders, to understand the customer experience and thereby get a new source of competitive advantage in the new economy (Prahalad \& Ramaswamy, 2004). However, the literature examining the mechanism of interaction between the constructs that permeate the customer experience began to emerge at the beginning of $21^{\text {st }}$ century (Zhang \& Chen, 2008) including the Brazilian academic scene. 
With the development of information technology, communications and internet, customers are influencing any business, anywhere in the world economy, so that no one organization can operate completely autonomously. The interaction between the organization and the customer forms the basis of the experience for the co-creation. The value creation process directs the focus to the customer and the co-creation experiences with the organization (Reay \& Seddighi, 2012).

In the paradigm of the co-creation experience, the customer participates in the creation and definition of value. Some models have emerged in the literature as how the customer interacts with the organization to co-create value. This research explores the models of Ueda etal. (2009), Payneet al.(2009), Elget al.(2012) and Grönroos (2011) and proposes, from the triangulation of them, an integrative and descriptive framework for experiences environment for value creation in health services.

The implementation of a platform for value creation in healthcare services depends on several controversial points, both methodological and practical, for proper planning and its implementation.

Analyze the way that healthcare industry develops services from the perspective of its customers and identify from them the aspects of technical and functional quality of its products and services figures as an important research question in healthcare (Elg et al, 2012).

The structure of this paper comprises, in addition to this introductory section, a section on the customer's participation in the creation of value, a section that describes the framework for the environment experience of co-creation in health care, a section that shows an example of the implementation of the framework and concludes with a section about the final considerations.

The next section presents a review of literature on customer participation in the creation of value, whose perspective is directed to the experience of co-creation.

\section{Customer Participation in Value Creation}

From the1960s, a globalized movement of customers is registered in relation to their rights to be informed, to be heard, to choose and security surrounding them. In health care, equal movement emerges in relation to the participation of the patients on aspects of attention to their health: diagnostic methods, treatment methods, objectives, patient education, decision making. The archetype of the passive patients, traditionally seen as passive spectators of the decisions about their health, moves to the role of patient involvement in decision-making about their health. The patient takes on a new archetype: active and reflective Customer, a person with will and right to self-determination. Like any other customer, the patients start to demand quality services assisting them (Longtin et al, 2010; Otani, 2010).

The concept of co-creation emerges from the idea of core competence. A core competence implies a collective learning in the organization, especially on how to coordinate a variety of production practices and integrate multiple technology streams to deliver value propositions. A core competence also implies communication, involvement and a deep employee commitment to work in organizational boundaries. The goal is to build a strong sense of community among people working in the organization: dialogues with customers and encounters with peers should be encouraged so that new opportunities can be discovered (Prahalad \& Hamel, 1990). Recent researches in the health area show the tendency of co-creation with the patient. There is a tendency to shift the archetype of the passive patients to the archetype of the active patients, who assume different roles in the provision of health care, operating as a resource or as a working resource for quality, satisfaction and value of their own care (Badcott, 2005; Elg et al, 2012.).

The evolution of Western democratic societies favored the development of individualism, so that it is expected that customers have greater responsibility for decisions about their own health (Beck \& Beck-Gernsheim, 2002). Instead of the customer passively accept the status quo, they consider alternatives, contrast different reasons and arguments, and form their own judgment. This is possible by access to information that is made available. Either as an individual or as a member of a social group, the way customers actively monitor their actions and the context in which they occur makes them a reflective customer (Newman \& Kuhlman, 2007).

In the traditional view, the customer is a passive recipient, separate and outside the organization (Payne, Storbacka \& Frow, 2008). This perspective is still predominant in health services (Berry \& Bendapudi, 2007). However, a new paradigm emerges, so that the customer can co-create value with 
the organization and with other stakeholders (Prahalad \& Ramaswamy, 2004; Vargo \& Lusch, 2004; Shau, Muniz \& Arnould, 2009). The customer changes the archetype "passive customer" to the archetype "active customer" (Payne, Storbacka \& Frow, 2008). The customers become endogenous to create value both for themselves and for the organization (Vargo \& Lusch, 2008a). They form a continuum in which the customer takes several active role levels in providing services and carrying out its benefits (Prahalad \& Ramaswamy, 2000; Vargo \& Lusch, 2004). The service provider is seen as a partial element that provides inputs to the value creation process for the customer, among other resources, including the activities of the customer themselves (Vargo \& Lusch, 2004).

The customer experience is a holistic construct that is a subjective response to the interaction between the customer and the service provider (Meyer \& Schwager, 2007). Customer satisfaction is one of the critical components of quality for the results of health services. The assessment of overall quality, the propensity to recommend the service and the propensity to return to service are different constructs arising from the customer experience with the various factors (dimensions or attributes) of health services (Otani, 2010).

The co-creation with the customer does not occur in a vacuum. Rather, this occurs within social systems in which people can learn, adapt and make choices based on their perceptions on the construction of social reality. The construction of meaning (sense making) implies social interactions as well as the identification of roles and positions of the actors within the social system (Edvardsson, Tronvoll \& Gruber, 2010).

The network experience environment, unlike the supply chains centered in organizations, comprises nonlinear relationships between the organization, the customer, the customer communities, partners, suppliers and other stakeholders. The connections network enables an environment for co-creation experience, so that each customer has a unique interaction. The client actively co-creates his/her personalized experience (Prahalad \& Ramaswamy, 2003).

The essential premise of the industrial paradigm is that products and services are the basis for value creation. The organization determines what should be produced or not, depending on customer demand. The value is transferred from the producer to the customer. The market becomes, then, the purpose of the demand for products and service offerings to customers. Thus, there is a shift to value chain systems as a basis for value creation. However, a new paradigm for value creation, whose principles are based on the creation of personalized customer experiences, emerges in the early twenty-first century (Prahalad, 2004; Prahalad \& Ramaswamy, 2004).

Differently from what happened in the past, customers are changing dialogue with health professionals. They want to be involved and understand the bases of diagnosis and treatment. Despite the health professionals not liking it, they do Internet searches about their health problems and challenge these professionals on the diagnosis, prescription and treatment modality. The immersion of the customers on the network information allows the risks and benefits of the decisions about their health to be revalued (Prahalad, 2004).

The basic premise of the new model of value creation is experience. This is put together with the organization and the customer. To thisnew concept, a new name was given, valueco-creation (Prahalad \& Ramaswamy, 2003). The experience of innovation involves chain links, extensibility (ability to grow by adding new components), granularity (subdivision into small pieces) and expansibility (tendency to occupy a growing space) (Prahalad \& Ramaswamy, 2003). There is need for networking experiences; services and smart products; dialog, access and transparency; customer communities; real-time action; understanding of the heterogeneity and complexity; alliances; quick reconfiguration of resources. Technologies and products are not a goal themselves, but act as experience vehicles (Prahalad, 2004).

Currently, the customer is no longer seen as a target, a single role of passive customer. The customer assumes an active position of producer. In this production process, the customers select the use and interactions of different products and services that are tailored to their needs. As customers become increasingly educated in comprehension (sensing), manipulation and construction skills, they become more able to participate in the control than merely reproduce what is externally controlled. The customer is seen in the postmodern era, then, as a co-producer, not merely an external element to the organization (Firat, Dholakia \& Venkatesh, 1995). 
The next section presents the proposed framework for a networked environment to experience value setting in health services, based on the triangulation of four theoretical models reviewed in the academic literature.

\section{Experience EnVironment Network for Value Creation in Health SERVices}

The viability of a health service developmental model, based on co-creation, requires planning and the management of controversial issues in a practical and methodological nature. Among these issues are the care process selection and the design of customer's data collection method, so that they can be transformed into valuable information (Elg et al., 2012).

Many research problems require a combination of different approaches to a better understanding of the phenomenon in question. The triangulation considers a research topic from at least two insider's perspectives, with several theoretical or methodological approaches. The triangulation theory considers a number of theoretical points of views, arranged side by side in order to assess their usefulness and their power, providing additional knowledge. Thus, the triangulation contributes to the quality of the research The triangulation may take various characteristics, but generally refers to the use of multiple data sources, data collection methods, research models. The main objective is to reduce the disadvantages of single use of a particular approach. Observations from different sources, different results may show or not a new phenomenon. The data juxtaposition can bring new perspectives on the phenomenon under study (Long \& Johnson, 2000).

This section presents a framework for an experience environment network for value configuration in health services. This framework was developed from the literature review. The research proposes a combination of approaches from Payne et al. (2009), Ueda et al. (2009), Grönroos (2011) and Elg et al. (2012).

\section{Models Selected in Literature}

Ueda et al. (2009) proposed a value creation model based on emerging synthesis. The synthesis involves the development of the system structure so it performs its function and therefore find a purpose within the constraints of environmental conditions (Figure 1). In other words, the emerging synthesis searches a function (purpose) to a structure (action).

The value has close relations with the creation of an artifact. The process begins with the analysis of knowledge about the existing environment, both natural and social. In the analysis phase, it matters collecting and selecting fragments of knowledge, and in the synthesis phase, creating a structure that incorporates some meaning to the artifact. The analysis represents the science of recognition, while the synthesis is the science of design. However, unless the device operates in the environment in which it is inserted, exchanged and used by people, it will not create value (Ueda, Takenaka \& Fujita, 2008).

Payne et al. (2009) defined a model of co-creation with emphasis on processes to create value propositions to the customer. The authors evoke a sense of the whole relationship between the service provider and its customer, both located in the same contexts of experience and frank and deliberate practice. The processes of meeting between both represent a series of interactions and transactions for their relationships, whose initiative can be of each party individually or both simultaneously. The meeting appears as the process in which both interact and mutually co-create highly dependent experiences of the context in which they are inserted (Payne et al., 2009).

Payne et al. (2009) proposed a model for co-creating relationship experience with the brand. The model consists in the process of value creation by the customer, in the process of value creation by the service provider, in the encounters between the service provider and the customer and in the impact of additional sources of brand awareness (Figure 1).

Grönroos (2011) proposed a connection between the processes of the service provider and the customer. The service provider must engage all your customer-related processes with the various corresponding processes of its customer (practice matching).

In a continuing business context, interactive contacts between the service provider and its customer occur, to a greater or lesser degree. The success of the service provider does not depend on how well it manages only the production of goods or delivery of services. The value to the customer does not only emerge from a single resource (main product or service), but of a whole complex of interactions between them, which ensure the successful use of resources (Grönroos, 2011). 
One-Day Biopsy: An Experience Environment for Value Co-Creation in Health Services

\begin{tabular}{|c|c|c|c|c|c|c|c|}
\hline \multicolumn{8}{|c|}{ Co-Creation Models Selected in Literature } \\
\hline \multicolumn{2}{|c|}{ Ueda et al. (2009) } & \multicolumn{2}{|c|}{ Payne et al. (2009) } & \multicolumn{2}{|c|}{ Grönroos (2011) } & \multicolumn{2}{|c|}{ Elg et al. (2012) } \\
\hline Process & Microprocess & Customer Process & Supplier Process & Customer Process & Supplier Process & Process & Microprocess \\
\hline \multirow{8}{*}{ Analysis } & Collection & \multirow{3}{*}{$\begin{array}{c}\text { Hedonic values, subjectivity \& } \\
\text { experiences }\end{array}$} & \multirow{3}{*}{$\begin{array}{l}\text { Co-creation } \\
\text { opportunities }\end{array}$} & \multirow{3}{*}{ Usage analysis } & \multirow{3}{*}{$P \& D$} & \multirow{3}{*}{ Preparation } & Select care process \\
\hline & \multirow{2}{*}{ Selection } & & & & & & Design process and diary \\
\hline & & & & & & & Select medium \\
\hline & \multirow{5}{*}{ Structuring } & $\begin{array}{c}\text { Emotion, Cognition \& } \\
\text { Behaviour }\end{array}$ & Planing & $\begin{array}{l}\text { Purchasing order } \\
\text { making }\end{array}$ & $\begin{array}{l}\text { Sales, Marketing, } \\
\text { Order processing }\end{array}$ & \multirow{5}{*}{ Execution } & Recruit patients \\
\hline & & \multirow{4}{*}{$\begin{array}{l}\text { Customer communities, user } \\
\text { inovation }\end{array}$} & \multirow{4}{*}{ Implementation } & Warehouse instaling & $\begin{array}{l}\text { Logistic delivery } \\
\text { instaling }\end{array}$ & & \multirow{4}{*}{ Support patients writing } \\
\hline & & & & \begin{tabular}{|l|} 
Paying cost control \\
\end{tabular} & Invoicing & & \\
\hline & & & & Usage & $\begin{array}{c}\text { Repair, maintenance, } \\
\text { operation }\end{array}$ & & \\
\hline & & & & Information need & Call-center, internet & & \\
\hline \multirow{3}{*}{ Synthesis } & \multirow{3}{*}{$\begin{array}{l}\text { Function } \\
\text { expression }\end{array}$} & \multirow{3}{*}{ Design } & \multirow{3}{*}{ Metrics } & & & \multirow{3}{*}{ Learning } & Process involvement team \\
\hline & & & & Problems, complains & $\begin{array}{c}\text { Complains handings, } \\
\text { recovery }\end{array}$ & & $\begin{array}{l}\text { Confort, diagnosis and } \\
\text { treatment autonomy }\end{array}$ \\
\hline & & & & $\begin{array}{l}\text { Upgrading, } \\
\text { modernization }\end{array}$ & $\begin{array}{l}\text { Engineering, } \\
\text { technoogy } \\
\text { development }\end{array}$ & & Staff educational process \\
\hline
\end{tabular}

Figure1. Co-creation models selected in the literature.

Elg et al. (2012) propose a model of customer co-creation and learning based on daily notes records of customers for the development of health services (Figure 1). The authors developed a model of cocreation and learning in health services for a holistic understanding of the customer's history and practices and experiences naturally embedded in this context. In health services, the customer, in general, is the only actor who experiences all the steps to solve a health problem, since the first clinical or laboratory manifestation of the problem to the contact with the network services. This includes the diagnosis, treatment, follow-up and rehabilitation.

Several issues need planning and management for the inclusion of co-creation in the development of health services, from the selection of care processes to the design of a method to capture its ideas to analyze the information and how to use them (Elg et al., 2012).

\section{Comparison of The Models}

The model from Elg et al. (2012) describes the process of co-creation with customers and learning through three phases: preparation, execution and learning.

The preparation phase consists in a stage of process selection of care for the experience of co-creation with the customer, from the data collection, process design and selection of the media to collect data (Elg et al., 2012). This phase is juxtaposed to the analysis phase (collection and selection) of Ueda et al model. (2009), which extracts the partial knowledge of all bodies of knowledge from existing things (environment, people, artifacts).

Therefore, by analogy, in order to the development of products and health services to exist, it is essential, at first, the collection of pieces of knowledge available. In addition, it follows the proper selection of the acquired knowledge to the design of health services (Figure2 - model input).

Considering the model of Grönroos (2011), there is an opportunity of connection of these phases (preparation / analysis) between the processes of the service provider and the customer. The customer process input begins with the product and services research available in the market that can meet his/her needs and expectations.

On the other hand, the service provider should collect customer data on expectations of products and services that matter to him/her. Then an opportunity for joint production of values between the service provider and the customer (co-development) emerges.

The customer subsequent sub-process consists in assessing the usefulness of the products and services provided by the service provider. Another emerging opportunity for the service provider to select the alternatives that are aligned with customer prospects (co-design of services).

A co-creative organization responds to the insights originated from engagement of experiences between people (the process-related stakeholders), designing and redesigning the effective value (Ramaswamy \& Gouillart, 2010), in practice matching (Grönroos, 2011; Payne et al, 2009).

The implementation phase includes the recruitment of customers and the support of their manifestations, being those needs or expectations (Elgetal., 2012). There is a correspondence with the organization step, synthesis phase, of Ueda et al. (2009). There are generally multiple possibilities of combinations and potential solutions that can meet customers' requirements. It makes emerge the composition of a new unit to be made available to the client (Ueda etal., 2009). 
The organization must align resource mobilization with its purchase by the customer. The resources mobilized, despite having some functionality, not necessarily add value to the customer. Unless the resources mobilized operate properly in the customer context, they are unlikely to add value to the customer experience (Ueda et al., 2009). The organization can also explore a competitive advantage by opting to co-produce the resources with patients.

\section{Model Proposal}

Figure 2 exhibits a proposal of model based on the literature review. The delivery mode and the usufruct mode of resources are the critical initial steps to co-creation and the shared decision-making in the meeting between the customer and the front-line staff (physician, nurse, practical nurse, physical therapist, nutritionist, psychologist, etc.).

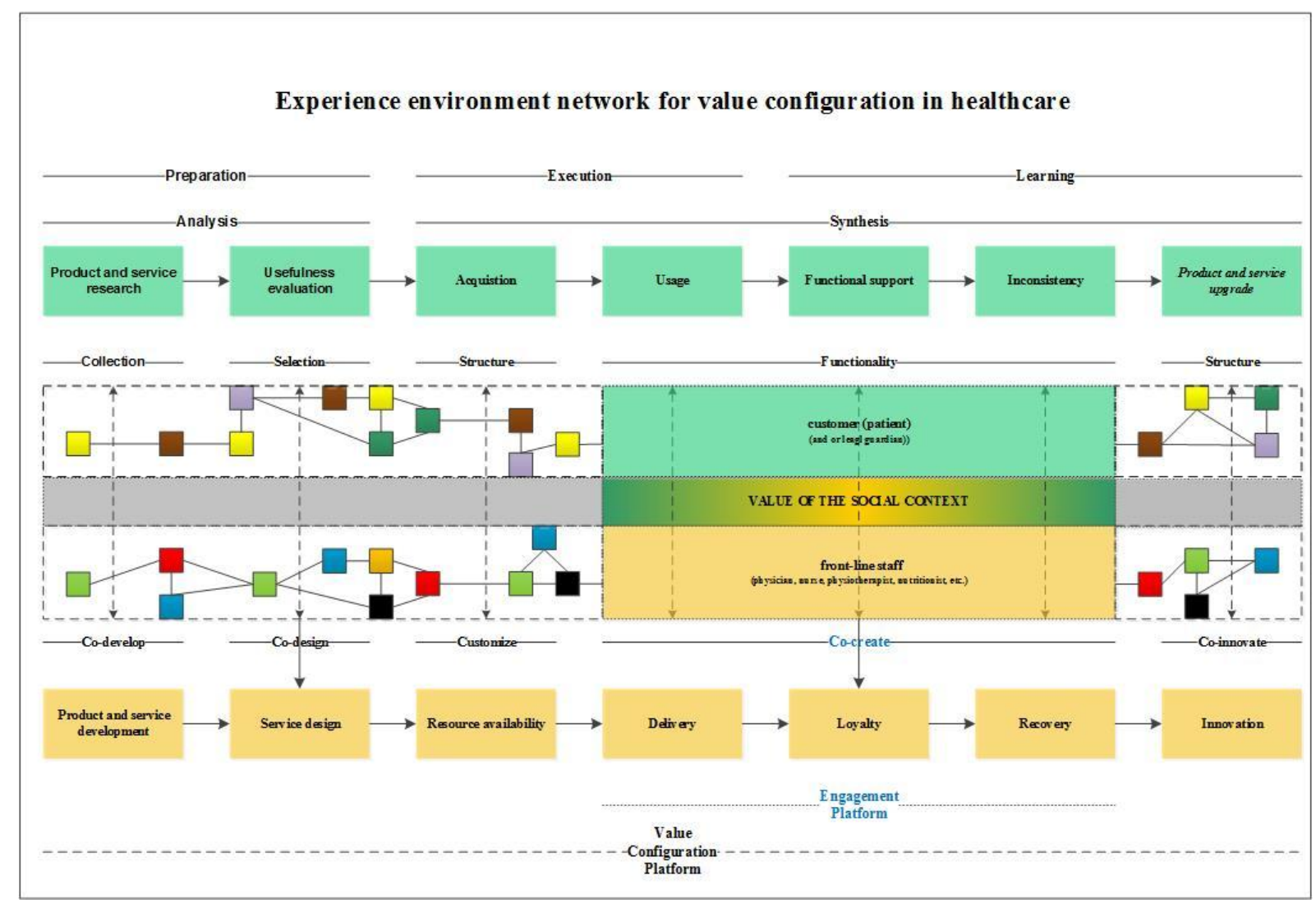

Figure2. Experience Environment Network for value configuration in the health service. Silva, 2014.

During the high contact encounters between the customer and the care front-line staff, opportunities of interactions for co-creation appear (use value). For a solid interaction, the building blocks submitted by Prahalad and Ramaswamy (2004) are needed: dialogue, access, evaluation of the risk / benefit and transparency.

The customers' experience is crucial for getting them interested in the co-creation process. It enters then the learning phase of Elg et al. (2012). Several learning modes emerge from the experience of cocreation. Customer ideas can be used as a basis for innovation and development of care processes; they can identify critical, positive or negative incidents in care processes; and they can contribute to a holistic understanding of the customer and the customer's perspective on the services executed (Elg et al., 2012).

The encounters are a series of interactions and transactions that occur during the relations between the customer and the front-line staff (both integrating resources). Either party may take the initiative of the meeting. The encounters are represented in Figure 2 by the dashed arrows with double direction. The two directions of the arrows are intended to emphasize the fundamental element of co-creation and service-dominant logic, i.e. the dialogue between the parties (Payne et al, 2009; Ballantyne \& Varey, 2006).

The shape and the mix of co-creative processes are highly dependent on specific contexts, whose variation depends on the nature and extent of the relationship. The co-creative encounters (colored 
rectangles with dotted edges) influence the customer's ability, desire and opportunity to co-create with the front-line staff. The brand communication and the attitude toward the brand are two aspects that facilitate co-creation (Payneetal., 2009).

The encounters might support the co-creation in a cognitive perspective: sense making ("Why should I get involved in this process?"). This contributes to the sharing of information and the development of expertise. They equally might provide emotional support (Payne et al., 2009). Emotional engagement is critical to customer loyalty, including making them an active promoter of the service. In addition, encounters may also provide functional support actions, so that the customer can engage in various activities, such as disease prevention and health promotion campaigns.

The exchange of services occurs in a broad setting space (rectangle with dashed edges that includes all the dashed arrows). Both parties are embedded in larger networks (employees' networks /customers' networks). In Figure2, the actors in their respective network are represented with different colors, symbolizing different roles and diversity. For example, the customer's network: family members, caregivers, friends, physicians, counselors, drugstores, laboratories, etc. These networks are complex adaptive service systems (Lusch, Vargo \& Wessels, 2008). They adapt to changes in the environment and are able to organize their resources to such adjustments. In addition, they are social systems because imply in interactions between the actors in various social contexts (Edvardsson, Tronvol \& Gruber, 2010). Each service system has a unique identity, and a story whose sequence involves episodes of interactions with other service systems and with itself (Spohrer et al., 2008).

The management of co-creation encounters modulates the content and experiences that are appropriate for the different phases of the interactions (Payne et al., 2009), since the delivery of services, through customer loyalty, until recovery services in non-compliance. Identify and mapping each of these steps might contribute to the understanding of how each party, customer and frontline staff, experience the interactions.

An exploitation of Grönroos' model (2011) might speculate that the value facilitation (co-development, co-design, customization, co-innovation, etc.) occurs in the front-line staff level, while the creation of value (value use) occurs in the customer's sphere. Seen from the perspective of value creation, the front-line staff is invited to engage in the customer process in order to facilitate his/her value creation. During the interaction, the frontline staff has the opportunity to learn from the customers, and can actively influence the flow and the result of their value creation process.

The flows of the front line staff and customer processes have some degree of parallelism between them. However, as suggested by Grönroos (2011), the mere existence of interaction does not imply that the action of one part affects the other one. The existence of the interaction, under the frontline staff's point of view, is merely an engagement platform (Ramaswamy \& Gouillart, 2010), an opportunity to influence (Grönroos, 2011) the customer process.

An organization can make the first attempt to apply the co-creation planning the engagement platforms. In the early stages, the engagement platforms are likesand boxes, an environment in which people collectively plan along with the organization its future and the way interactions occur. This requires experimentation and learning, trial and error attempts. Engagement platforms evolve by increments of trial and error over time (Ramaswamy \& Gouillart, 2010).

\section{Clodomiro Amazonas One-Day Biopsy Engagement Platform}

Clodomiro Amazonas Breast Cancer Diagnosis Center is a Brazilian Diagnosis Center, in São Paulo, where time to treat breast cancer has become a top quality measure priority. Time to surgery is associated with lower overall and disease specific survival. Each 30-day delay in time to breast cancer surgery was found to be associated with lower survival (Bleicher et al., 2016). Some women can wait up to 180 days from the time from their diagnosis to the time they underwent surgery.

For women with breast cancer, adverse outcomes are associated with delaying initiating of adjuvant chemotherapy 91 days or more (Chaves-McGregor, Clarke, Lichetensztajn, \& Giordano, 2016). The treatment should be started as soon as possible after breast cancer is diagnosed (Caplan, 2014). After the first 30 days after the diagnosis, each 30-delay in surgery is associated with a $10 \%$ decrease in survival (Bleicher et al, 2016). 
Clodomiro Amazonas has implemented a co-creative model do develop a shared breast cancer diagnosis agenda linked to time to surgery. It was designed a different supplier process with people who engage with it (Figure 3).

\begin{tabular}{|c|c|c|c|c|c|c|c|c|c|c|c|c|c|c|c|}
\hline & 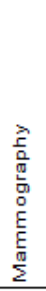 & 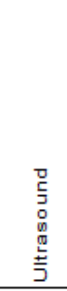 & 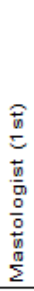 & $\begin{array}{l}\overrightarrow{0} \\
\frac{0}{0} \\
\frac{0}{0}\end{array}$ & 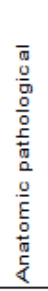 & 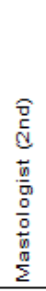 & 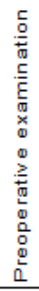 & 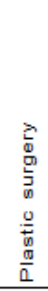 & 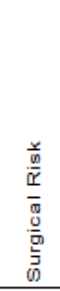 & 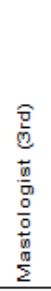 & $\begin{array}{l}\overrightarrow{0} \\
\mathbb{0} \\
\stackrel{5}{3} \\
0\end{array}$ & 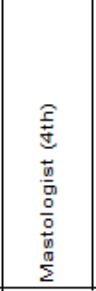 & 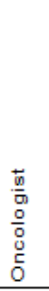 & $\begin{array}{l}\frac{\lambda}{a} \\
\frac{0}{\pi} \\
\frac{0}{5} \\
\frac{5}{0} \\
\frac{g}{0} \\
\frac{5}{0} \\
\frac{5}{0}\end{array}$ & $\begin{array}{l}\bar{\sigma} \\
\stackrel{\sigma}{\circ} \\
⺊\end{array}$ \\
\hline 1st Stage & & 7 & 7 & 7 & 3,4 & 21 & \multicolumn{3}{|c|}{7} & 21 & 21 & 21 & & & 1154 \\
\hline 2nd Satge & \multicolumn{4}{|c|}{1} & 3,4 & 1 & & 2 & & 1 & 15 & 7 & & & 30,4 \\
\hline Target & \multicolumn{4}{|c|}{1} & 2 & & & & & 1 & 1 & 7 & 2 & 1 & 17 \\
\hline \multirow{2}{*}{ Framew ork } & \multicolumn{6}{|c|}{ Preparation } & \multicolumn{5}{|c|}{ Execution } & \multicolumn{4}{|c|}{ Learning } \\
\hline & \multicolumn{6}{|c|}{ Analysis } & \multicolumn{9}{|c|}{ Synthes is } \\
\hline \multirow{2}{*}{ Supplier Process } & \multicolumn{4}{|c|}{ Service Development } & \multicolumn{2}{|c|}{ Service des ign } & \multicolumn{3}{|c|}{ Res ource availabiity } & \multicolumn{2}{|c|}{ Delivery } & Loyalty & \multicolumn{2}{|c|}{ Recovery } & $94 \%$ \\
\hline & \multicolumn{4}{|c|}{ Co-develop } & \multicolumn{2}{|c|}{ Co-design } & \multicolumn{3}{|c|}{ Cus tomize } & \multicolumn{5}{|c|}{ co-reation } & Innovation \\
\hline
\end{tabular}

Figure3. Clodomiro Amazonas Breast Cancer Diagnosis Center-Co-creation Engagement Platform.

Most patients waited up to 250 days from the time they were diagnosed to the time they underwent surgery (Figure 3). The development of the engagement platform involved experimentation and leaning. It is almost impossible to build a co-creative platform to ensure to the patients a perfect experience right out of the gate. It evolves in trial-and-errors increments. The co-creators often changed the supplier process significantly over time.

The time of Collection Process was reduced from 153 days to 1 day. This new design evolved ongoing interactions among co-creators, expanding the space of experiences (diagnosis center and medical clinics). This was main change in the supplier process and was named One-Day Biopsy Program. This has ensured participants a perfect experience right out of the gate

The overall process was reduced from 270 days to 17 days. The co-creation model could take additional steps to strengthen the engagement among diagnosis center, medical clinics and hospitals and collaboration with women and others stakeholders. The customer's experience is not merely related to the use of Clodomiro Amazonas's resources, or involved network, or the quality of health care staff. The experience is the result of the degree of involvement in the process and the value is the creative combination that generated the whole experience for the women with breast cancer. Clodomiro Amazonas is seen as the vehicle of experience, according to Prahalad (2004)

\section{Closing Remarks}

The co-creation process has a potential to generate effective solutions through multiple interactions between the various elements of a global system. The artifacts, people and society, in this second decade of 21 st century, are closely interrelated, so that the value creation emerges through the interaction between these three elements. Moreover, both the generation of products and the creation of services require an understanding under a unique perspective of value creation. In the co-creation concept, the product or the service value provider, as well as the value customer cannot be determined independently. The separation between them is not viable due to the interaction within each other (Ueda; Takenaka \& Fujita, 2008).

The service-dominant logic suggests that value creation begins when a service provider understands the process of customer value creation and learn how to support for co-creation activities to him/her (Vargo \& Lusch, 2004). Prahalad (2004) stated that the value creation is embedded in personalized experiences.

The concept of service undergoes a paradigm shift, the creation of a market offering for a perspective of value creation. The service-dominant logic directs the focus to the value of the context and the result of customer's experience. In other words, the customer must be involved and the use of the 
situations are critical to the value creation understanding. Thus, the value must be evaluated through the customer's experience lenses. The focus shifts from the service or the product themselves to the value creation process and its result (Edvardsson etal., 2012).

Edvardsson et al. (2012) argued that questions related to the nature of services (activities, collaboration, customers as integration resources and the co-creation) need a framework to learn critical and useful information for the understanding of customer service experience and co-creation process.

Vargo and Lusch (2008b) argued that co-creation is an experience accessed when the service is performed within the customer context. Thus, the customers use their skills (knowledge and abilities) in combination with the organization's resources (or more organizations). The actors, based on experience in each context, determine the value, under this perspective. The value of the context indicates that not only the co-creation phenomenon but also the value is dependent on the integration of other resources, defined and estimated in each context (Edvardsson, et al., 2012).

Therefore, value creationis a social construction. Thus, social forces shape up co-creation, which is generated in social structures and is presented, sometimes asymmetrically between the various social actors. The actors learn and change their roles within dynamic service systems (Edvardsson, Tronvoll \& Gruber, 2010).

Both service providers and customers are actors tied to service system networks and act as resource integrators (Vargo, 2008). The service-dominant logic directs its focus to orientation process rather than orientation outputs (goods and services). This implies in customer engagement to co-create value (Vargo \& Lusch, 2008b). Services exchange and the perceived value are tied in social systems in which customers and organizations set defined positions and roles (Edvardsson, Tronvoll \& Gruber, 2010).

The service-dominant logic directs the focus to the concept of value use, that is, it refers to the concept that the value is co-created through interactions of system services that integrate and use the resources, being them owned or from others. By extension, it seems logical that the resources, which are used positively, correspond to a benefit for the system. However, at some time, one can also use it negatively. For example, consider a customer who buys a car and does not take care of its maintenance. Further, this customer can destroy the organization value that sold him/her the car if he/she blames the organization for the problems he/she is encountering with its use. Therefore, he/she is responsible for damaging the organization's image through the dissemination of its unfavorable opinion about the value proposition for others. In other words, this customer triggers a co-destructive process for both parties by misuse of value proposition (Plé \& Cáceres, 2010). This situation represents a practice of active opportunism by the customer (Ertimur \& Venkatesh, 2010).

Furthermore, in Brazilian health services, for example, the National Health Agency (ANS in Portuguese) has launched the Program of Health Service Providers Qualification (QUALISS in Portuguese) to increase the power of reviewing and selection of service providers by the beneficiaries of health insurance plans. Within the essential hospital indicators, there are two of them focused on the patient centrality: customer satisfaction and customers opinion monitoring: complaints and suggestions review (ANS, 2013). Therefore, in Brazil, starting from a measure of a regulator (ANS), health services providers must pay attention to the interaction between health care staff and the customer.

This theoretical paper proposed a framework for an experience environment for value configuration in health services. In addition, exploratory studies on opportunistic activities and value co-destruction experiences that permeate interactions between the customer and the service provider become important for both academic and administrative areas.

Another research opportunity includes the customers 'networks patterns and the health care front line staff's ones.

Additional studies to analyze what proceeded and what resulted from the co-creation experience also get academic and administrative importance. It is interesting, for academic research, to empirically explore this platform and understand the way this interaction process has positive or negative effects at each point of the framework. 
Customer-centric value creation processes may be associated to satisfaction with the service provided and may facilitate customer adherence to the rehabilitation programs, health promotion and disease prevention (Martin et al., 2005), what might bring economic impacts to the organization (Berry \& Bendapudi, 2007).

An extensive systematic review of the literature for empirical evidence to improve the framework structure becomes essential. A dynamic research, with longitudinal perspective, despite the operational difficulties, may provide, or not, support for the model to capture an association between variables identified in the academic literature to sustain an experience environment for co-creation in health services.

This paper can be valuable as a means of pulling together what is known about co-creation frameworks, not simply assembling and describing past work but rather building a theory to be tested.

Clodomiro Amazonas Breast Cancer Diagnosis Center is a successful form of engagement platform where people congregate with the specific purpose and a structured process through which they will co-create, thereby playing a central role in the health service experience to qualify breast cancer care and address it in a timely manner.

\section{REFERENCES}

ANS - AGÊNCIA NACIONAL DE SAÚDE SUPLEMENTAR. 2014. QUALISS - Indicadores hospitalares essenciais. Retrieved from http://www.ans.gov.br/espaco-dos-prestadores/qualiss/ 2044-qualiss-indicadores-hospitalares-essenciais-201314.

Badcott, D. 2005. The expert patient: valid recognition or false hope? Medicine, Health Care and Philosophy, 8(2): 173-178.

Ballantyne, D., \& Varey, R.J. 2006. Creating value-in-use trough marketing interaction: the exchange logic of relating, communicating and knowing. Marketing Theory, 6(3):335-348.

Beck, U., \& Beck-Gernheim, E. 2002. Individualization. London: Sage,

Bendapudi, N., \& Leone, R.P. 2003. Psychological implications of customer participation in co-production. Journal of Marketing, 67:14-28.

Berry, L.L., \& Bendapudi, N. 2007. Health care: a fertile field for service research. Journal of Service Research, 10(2): 111-122.

Bleicher, R.J. et al. 2016. Time to surgery and breast cancer survival in the United States. JAMA Oncol 2(3): 330-339.

Caplan, L. 2014. Delay in breast cancer: implications for stage diagnosis. Front Public Health, 2:87. doi: 10.3389/fpubh.2014.00087. eCollection 2014.

Chaves-McGragow, M., Clarke, C.A., Lichetensztajn, D.Y., \& Giordano, S.H. 2016. Delayed initiation of adjuvant chemotherapy among patients with breast cancer. JAMA Oncol, 2(3): 322329.

Edvardsson, B.,Tronvoll, B., \& Gruber, T. 2010. Expanding understanding of service Exchange and value co-creation: a social construction approach. Journal of Academy of Marketing Science, 39:327-339.

Edvardsson, B. et al. 2012. Customer integration within service development - A review of methods and analysis of insitu and exsitu contributions. Technovation, 32:419-429.

Elg, M. et al. 2012. Co-creation and learning in health-care service development. Journal of Service Management, 23(3): 328-343.

Ertimur, B., \& Venkatesh, A. 2010. Opportunism in co-production: implications for value co-creation. Australasian Marketing Journal, 18: 256-263.

Firat, A.F.,Dholakia, N., \& Venkatesh, A. 1995. Marketing in a postmodern world. European Journal of Marketing, 9(1): 40-56.

Grönroos, C. 2011. A service perspective on business relationship: the value creation, interaction and marketing interface. Industrial Marketing Management, 40: 240-247.

Long, T., \& Johnson, M. 2000. Rigour, reliability and validity in qualitative research. Clinical Effectiveness in Nursing, 4:30-37. 
Longtin, Y. et al. 2010. Patient participation: current knowledge and applicability to patient safety. Mayo Clin Proc, 85(1): 53-62.

Martin, L.R., Williams, S.L., Haskard, K.B.,\& DiMatteo,M.R. 2005. The challenge of patient adherence. Therapeutics and Clinical Risk Management, 1(3):189-199.

McColl-Kennedy, J.R. et al. 2012. Health care customer value co-creation practice styles. Journal of Service Research, 15(4): 370-389.

Meyer, C.,\&Schwager, A. 2007. Understanding customer experience. Harvard Business Review, $85: 116-126$.

Newman, J.,\& Kuhlman, E. 2007. Consumers enter the political stage? The modernization of health care in Britain and Germany. Journal of European Social Policy, 17(2): 99-111.

Ostrom, A.L. et al.2010. Moving forward and making a difference: research priorities for the service sciences. Journal of Service Research, 13(1): 4-36.

Otani, K. 2010. How patients reactions to hospital care attributes affect the evaluation of overall quality of care, willingness to recommend, and willingness to return. Journal of Healthcare Management, 55(1): 25-37.

Payne, A. F., Storbacka, K.,\&Frow, P. 2008. Managing the co-creation of value. Journal of the Academy Marketing Science, 36(1): 83-96.

Payne et al. 2009. Co-creating brands: diagnosing and designing the relationship experience. Journal of Business Research, 62: 379-389.

Plé, L., \& Cáceres, R.C. 2010. Not always co-creation: introducing interactional co-destruction of value in service-dominant logic. Journal of Services Marketing, 24(6): 430-437.

Prahalad, C.K. 2004. The blinders of dominant logic. Long Range Planning, 37: 171-179.

Prahalad, C.K., \& Hamel, L. G. 1990. The core competence of corporation. Harvard Business Review, 68(3): 79-91.

Prahalad, C.K.,\& Ramaswamy, V. 2000. Co-opting customer competence. Harvard Business Review, 78:79-90.

Prahalad, C.K., \& Ramaswamy, V. 2003. The new frontier in experience innovations. Sloam Management Review, 44(4):12-18.

Prahalad, C.K., \& Ramaswamy, V. 2004. Co-creation experiences: the next practice in value creation. Journal of Interactive Marketing, 18(3): 5-14.

Ramaswamy. V.,\&Gouillart, F. 2010. The power of co-creation: build it with them to boost growth, productivity and profits. New York: Free Press.

Reay, P.,\& Seddighi, H.R. 2012. An empirical evaluation of management and Operational capabilities for innovation via co-creation. European Journal of Innovation Management, 15(2): 259-275.

Shau, H., Muniz, A.A.,\&Arnould, E.J. 2009. How brand community practices create value.Journal of Marketing, 73:30-51.

Silva, A.S. 2014. Um modelo de antecedentes para a cocriação de valores em serviços de geriatria na cidade de São Paulo. Uma aplicação da modelagem de equações estruturais. (Unpublished master's dissertation). São Caetano do Sul. Universidade Municipal de São Caetano do Sul, Brazil.

Spohrer, J. et al.2008. The service system is the basic abstraction of service science. In: Hawaii International Conference on System Sciences, 41, 2008, Hawaii. Proceedings... Hawaii...

Spohrer, J. et al. 2010.An integrated SS-VSA analysis of changing job roles. Service Science, 2(1-2):1-20.

Ueda, K., Takenaka, T., \& Fujita, K. 2008. Toward value co-creation in manufacturing and servicing. CIRP Journal of Manufacturing Science and Technology, 1: 53-58.

Ueda, K. et al. 2009. Value creation and decision-making in sustainable society. CIRP Annals - Manufacturing Technology, 58: 681-700.

Vargo, S. L. 2008. Customer integration and value creation: paradigmatic traps and perspectives. Journal of Service Research, 11(2): 211-215. 
Vargo, S.L.,\& Lusch, R.F. 2004. Evolving to a new dominant logic for marketing. Journal of Marketing, 68(1): 1-17.

Vargo, S.L., \& Lusch, R.F. 2008a.Why service? Journal of the Academy of Marketing, 36, (1): 25-38.

Vargo, S.L., \& Lusch, R.F. 2008b.Service-dominant logic: continuing the evolution. Journal of the Academy of Marketing Science, 36(1): 1-10.

Verhoef, P.C. et al. 2009. Customer experience creation: determinants, dynamics and managements strategies. Journal of Retailing, 85(1): 31-41.

Zhang, X.,\& Chen, R. 200. Examining the mechanism of value co-creation with customers. Int. J. Production Economics, 116: 242-250. 